\title{
Intrauterine Foam Dosage Form
}

National Cancer Institute

\section{Source}

National Cancer Institute. Intrauterine Foam Dosage Form. NCI Thesaurus. Code C149616.

Liquid preparation for veterinary use, usually presented in a pressurized container provided with an applicator suitable for delivery to the uterus of foam containing large volumes of gas dispersed in a liquid containing the active substance(s). 